
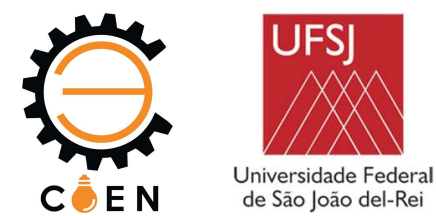

\title{
MONITORAMENTO DE GRAXAS LUBRIFICANTES EM CONDICÕES CRÍTICAS DE TEMPERATURA
}

\author{
Gustavo Rodrigues Lacerda (gu-lacerda@hotmail.com) ${ }^{(1)}$, \\ Vinicius Augusto Diniz Silva (viniciusadsilva@ufsj.edu.br) ${ }^{(1)}$ \\ ${ }^{(1)}$ Universidade Federal de São João Del Rei (UFSJ) - Engenharia Mecânica - Praça Frei Orlando, 170
}

RESUMO: Os lubrificantes são substâncias que emergidas entre duas superfícies, formam uma película protetora que tem por função principal reduzir o atrito, o desgaste, como também auxiliar no controle da temperatura e na vedação dos componentes de máquinas e motores, proporcionando a limpeza das peças, protegendo contra a corrosão decorrente dos processos de oxidação, evitando a entrada de impurezas. Dentre esses lubrificantes se destaca a graxa, um lubrificante pastoso de alta viscosidade, compostos de misturas de óleos lubrificantes minerais, sais de ácidos graxos, como cálcio, sódio, lítio, alumínio, bário e magnésio. A partir disso, foi determinado três tipos de graxas: graxa de Sabão de Lítio de viscosidade media, graxa a base de Cálcio de alta viscosidade, e por último a graxa de Hidróxido de Cálcio de viscosidade alta. Assim foram analisados esses três tipos de graxas em uso sobre um rolamento as diversas temperaturas utilizando o Kit de Teste para Graxa SKF-TKGT 1 para verificar a consistência e a propriedade das mesmas juntamente com a Câmera Termográfica SKT para monitorar a temperatura no interior do rolamento. Por conseguinte, deferir qual é a menos adequada para esse tipo de experimento. Tal analise ainda é pouco aderida por se tratar de comportamentos específicos devido à complexidade de conhecer seus componentes para poder analisá-los

PALAVRAS-CHAVE: Lubrificantes. Teste de Consistência, Teste de Sangria. Viscosidade.

\section{INTRODUÇÃO}

O crescimento da competitividade e os novos desafios relacionados com o aumento de produtividade entre as indústrias têm exigido sistemas cada vez mais complexos e sofisticados, por isso, o sistema de monitoramento da condição dessas máquinas tem se tornado muito importante (SILVA et al., 2009).

Manutenção preditiva é definida como manutenção que permite garantir uma qualidade de serviço desejada, com base na aplicação de técnicas de análise, utilizando-se meios de supervisão ou de amostragem (OLIVEIRA, 2012). Conforme Souza (2011), manutenção preditiva é aquela que indica as condições reais de funcionamento das máquinas com base em dados que informam os seus desgastes ou processo de degradação.

Dentre as inúmeras técnicas de manutenção preditiva, a termografia permite o acompanhamento de temperatura e a formação de imagens térmicas, denominada de termogramas. Ela, em geral, se sobressai sobre a outras devido a grandeza que ela trabalha, a temperatura, um dos parâmetros de mais fácil compreensão e o acompanhamento de sua variação. A sua utilização é muito importante 

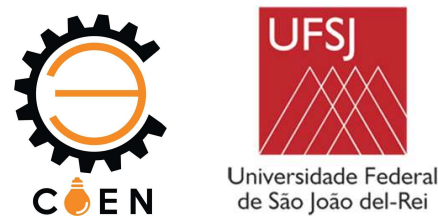

tanto para equipamentos elétricos como mecânicos, pois permite constatar uma alteração na condição de equipamentos, componentes e do próprio processo como um todo (SOUZA, 2011).

De acordo com os trabalhos publicados pelo Electric Power Research Institute (EPRI) em 1985 e pelo Institute of Electrical and Electronics Engineers, Inc. (IEEE) em 1986, os problemas nos rolamentos são responsáveis por dois quintos de todas as falhas em maquinas que tem maiores velocidades (STACK et al., 2003).

Dentre as causas mais comuns de defeitos em rolamentos destacam-se a seleção incorreta, estocagem e lubrificação inadequada (excessiva ou insuficiente), falha de vedação e descargas elétricas através dos mancais (BRITO, 2002).

Os lubrificantes têm como principal função o controle do atrito entre os componentes, a redução do desgaste, a transmissão de força, o controle da temperatura, amortecimento de choques, dentre outras. Desta forma, falhas ou deficiências na lubrificação podem acarretar sérias consequências, como: aumento da temperatura de funcionamento da máquina em decorrência do atrito, nível de desgaste superior ao normal das peças que estão em constante movimento, deficiência na transferência de forças, aumento da corrosão devido à ação das substâncias agressivas aos metais e incorretas absorções dos impactos (CAVALCANTI, 2007).

De acordo com Tecnolub (2011), as graxas são largamente utilizadas para lubrificação de mancais de rolamento em condições normais de operação, ao passo que o óleo é empregado quando as altas rotações e temperaturas impedem o uso da graxa. As graxas são uma mistura de óleo base e agente espessante. A maior parte dos espessantes são chamados sabões metálicos e podem ser a base de lítio, cálcio, sódio e alumínio (BRITO et al., 2011).

O objetivo desse trabalho é dar continuidade aos estudos sobre lubrificação em rolamentos, verificar as propriedades dos diferentes de tipos de graxas a condições críticas. A conclusão desse trabalho subsidiará o desenvolvimento de um trabalho posterior que tem por finalidade caracterizar possíveis falhas em rolamentos em estudo.

\section{FUNDAMENTAÇÃO TEÓRICA}

\subsection{TERMOGRAFIA}


A técnica termográfica mais usada na indústria é a comparação termográfica. Esta comparação pode ser quantitativa ou qualitativa. A termografia quantitativa é um método utilizado para avaliar a condição do equipamento, através da comparação dos valores de temperatura com equipamentos idênticos, valores de referência ou limites. Um exemplo deste método é o caso de duas máquinas que estejam a funcionar no mesmo ambiente sob as mesmas condições, e uma apresenta uma temperatura superior à outra. E provável que uma condição de deterioração possa existir. (CAMPOS , 2011).

O método de comparação qualitativo é idêntico ao anterior. Contudo, em vez de utilizar a comparação de valores utiliza uma imagem padrão termográfica. Embora as medições qualitativas possam detectar deficiências, é através das medições quantitativas que se tem a capacidade para determinar a gravidade das falhas em equipamentos mecânicos. (CAMPOS, 2011).

\subsection{ROLAMENTOS}

Os rolamentos são uma das peças de máquina mais comumente usadas pois seu movimento de rolamento torna quase todos os movimentos mais fáceis e ajudam a reduzir a fricção (NSK, 2019).

Os rolamentos suportam e guiam, com o mínimo de atrito os elementos rotativos ou oscilantes como eixos ou rodas - das máquinas e transferem as cargas entre os componentes da máquina. Eles oferecem alta precisão e baixo atrito; por isso, permitem velocidades de rotação altas enquanto reduzem o ruído, o calor, o consumo de energia e o desgaste. Além disso, são elementos econômicos e substituíveis que normalmente seguem padrões de dimensão nacionais e internacionais (SKF, 2019).

\subsection{GRAXAS LUBRIFICANTES}

\subsubsection{GraXa AZUl (SABão de Lítio):}

É recomendada para múltiplas aplicações, produzida com sabão de lítio e óleo de viscosidade média, conta com aditivos para assegurar boa estabilidade mecânica, proteção contra oxidação e resistência ao calor moderado, seu grau NLGI é 2, segundo o fabricante. Tal lubrificante é apresentado na Figura 1. 


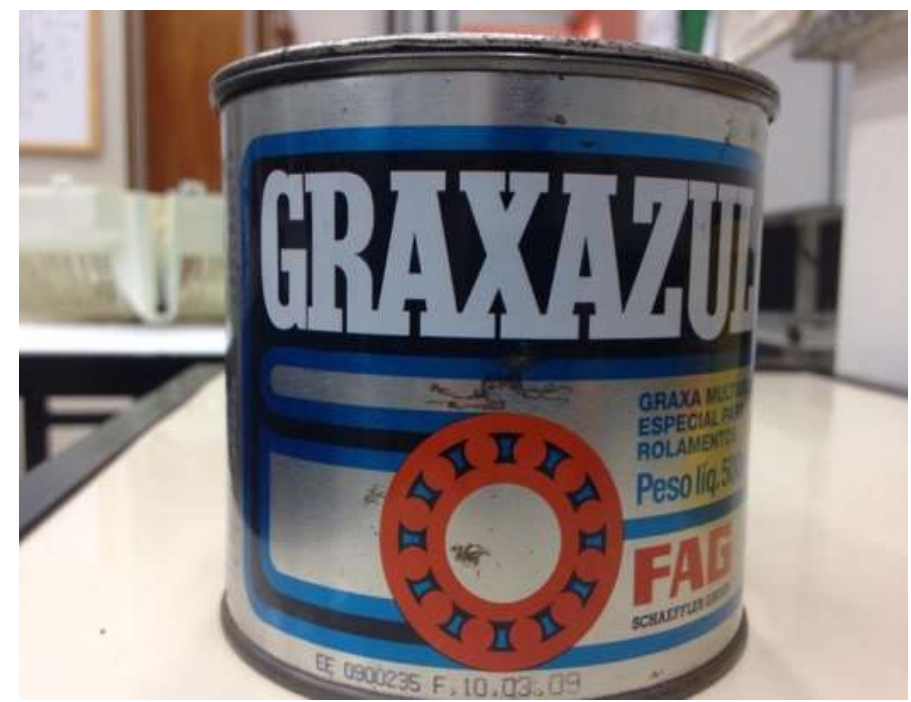

Figura 1. Graxa com sabão de Lítio. Fonte: Autor (2019).

\subsubsection{Unigrax CA (BASE de CÁlCIO):}

A Unigrax CA é uma graxa à base de cálcio, hidro-repelente, fabricada com óleo lubrificante de alta viscosidade, tendo uma cor castanha escura e grande adesividade. Recomendada para lubrificação das articulações de chassis de caminhões, automóveis, tratores, motocicletas,mancais de deslizamento, seu grau NLGI é 2, de acordo com o fabricante. A mesma é exposta na Figura 2.

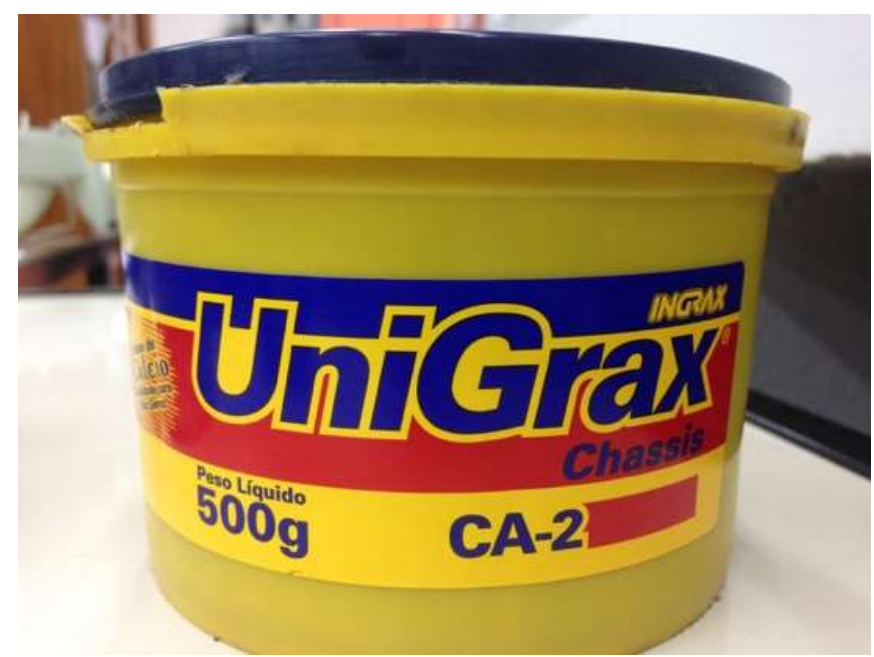

Figura 2. Graxa com sabão de Lítio. Fonte: Autor (2019) 


\subsubsection{GraXinha (HidRóXIdo de CÁlCIO):}

A graxa preta tem em sua composição óleo mineral, aditivo de adesividade e hidróxido de cálcio, sendo recomendada para lubrificação geral de automóveis e uso doméstico. Apresenta-se grande flexibilidade de aplicações, excelente resistência à oxidação e à corrosão e boa adesividade a diversas superfícies. O material discutido exemplifica na Figura 3 a seguir.

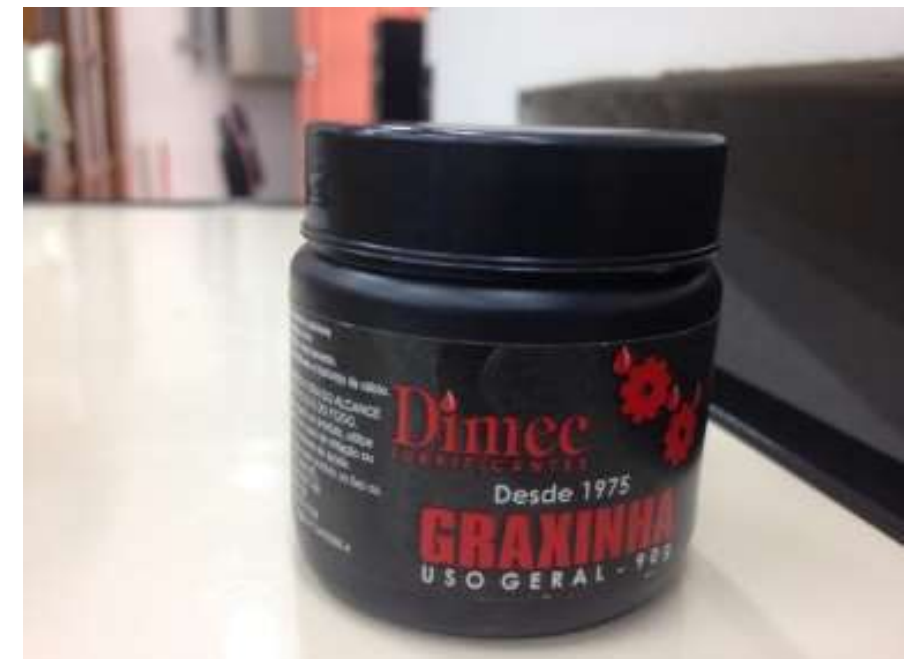

Figura 3. Graxa de Hidróxido de Cálcio. Fonte: Autor (2019)

\section{MATERIAIS E MÉTODOS}

\subsection{TESTE DE CONSISTÊNCIA}

A principal propriedade dos óleos lubrificantes é a viscosidade, já a da graxa é a consistência. Através da consistência é possível determinar a rigidez da graxa e auxiliar em um diagnóstico tanto para o equipamento quanto para a graxa, (SKF, 2011).

O método de teste de consistência está de acordo com a norma ASTM D217. Tem como o princípio a medição do grau de penetração de um cone padrão em uma amostra da graxa e convertido em termos de grau NLGI (National Lubrification Grease Institute) (ASTM, 2010).

Com o TKGT 1 da SKF, é possível determinar, em campo, a consistência da graxa. A técnica se dá pela aplicação de uma certa quantidade de graxa, e pressionada por um peso entre duas placas de vidro durante 15 segundos. Com uma escala calibrada, que se determina o grau NLGI, (SKF, 2011). Assinalada na Figura 4 a seguir. 

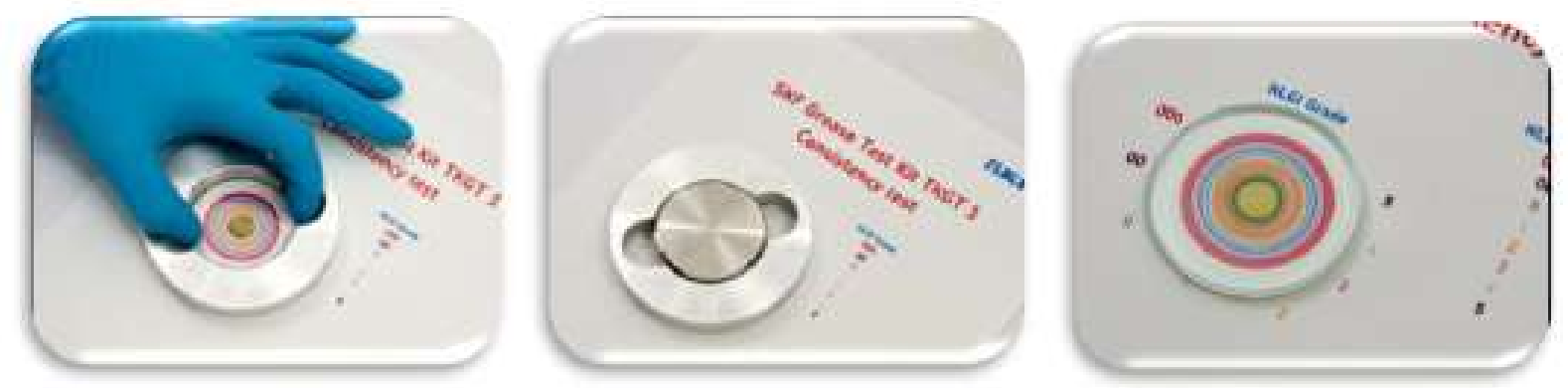

Figura 4. Teste de Consistência. Fonte: Instructions for Use - Test Kit Analysis Grease TKGT 1.

\subsection{TESTE DE SANGRIA}

No teste de sangria uma quantidade fixa de graxa é colocada em um pedaço de papel mata-borrão fornecido. Aquecendo este papel por duas horas, o óleo base será liberado da graxa e criará uma mancha de óleo no papel. A mudança nas propriedades de sangramento pode ser avaliada através da medição do diâmetro da mancha formada, cálculo da área sangrada e comparação com a área dada por uma amostra fresca não usada. Tal teste analisa as mudanças nas propriedades da graxa. Indicada na Figura 5.
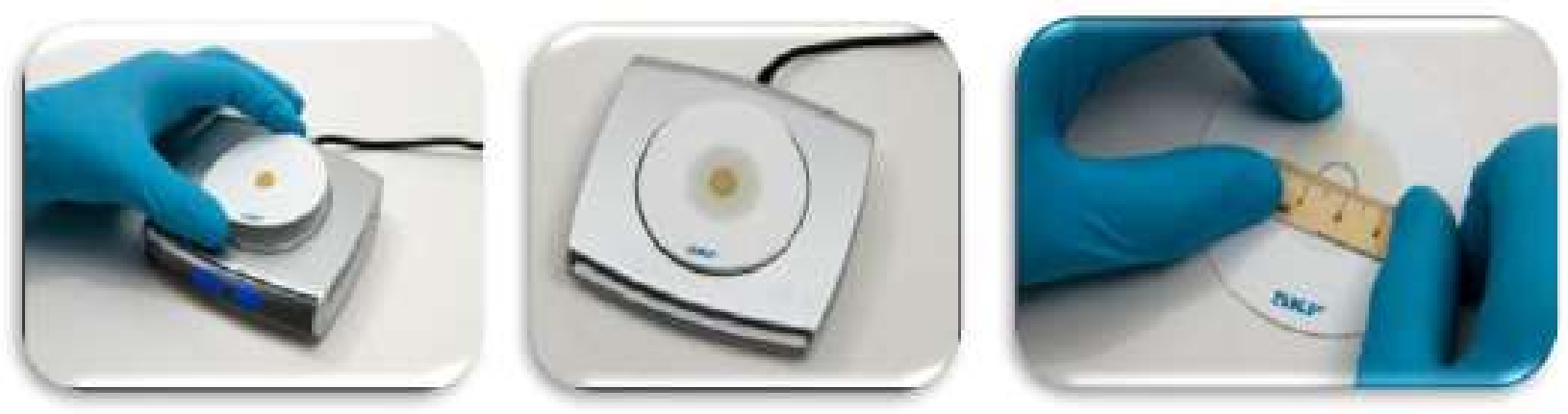

Figura 5. Teste de Sangria. Fonte: Instructions for Use - Test Kit Analysis Grease TKGT 1.

\subsection{ROLAMENTOS}

Dentre os diversos tipos de rolamentos, foi escolhido o rolamento rígido de esferas, na qual tem a função de transmitir movimento rotacional sem perda de energia. Para esse fim, os rolamentos de baixo atrito são geralmente compostos por dois anéis de aço temperado SAE 52100, separados pelas 
esferas e espaçados por uma gaiola. São indicados, para velocidades altas e muito altas, assim como, suportam cargas radiais e axiais em ambas as direções e exigem pouca manutenção.

Com tais características foram utilizados três rolamentos, um para cada graxa mencionada, com dimensões $52 \mathrm{~mm}$ de diâmetro externo e $25 \mathrm{~mm}$ de diâmetro interno da marca GBR Bearing.

\subsection{CONTROLE DE RISCO DE CONTAMINAÇÃo}

Para a limpeza foi contemplada de um solvente, querosene, que não deixa resíduos para a limpeza das superfícies dos rolamentos proporcionando a condição ideal de lubrificação, como também evita o risco de contaminações, contribuindo assim para o aumento da vida útil do rolamento, tal material é amplamente usado no comercio e em industrias.

\subsection{BANCADA}

Foi utilizado um motor monofásico acoplado a uma polia de $90 \mathrm{~mm}$ de diâmetro, que por sua vez transmite sua rotação a outra polia de $150 \mathrm{~mm}$ de diâmetro, ambas fabricada em ferro fundido cinzento FC 150. Por fim, o rolamento com a graxa a ser estudada está inserido na polia maior. Tal bancada é apresentada na Figura 6 a seguir.

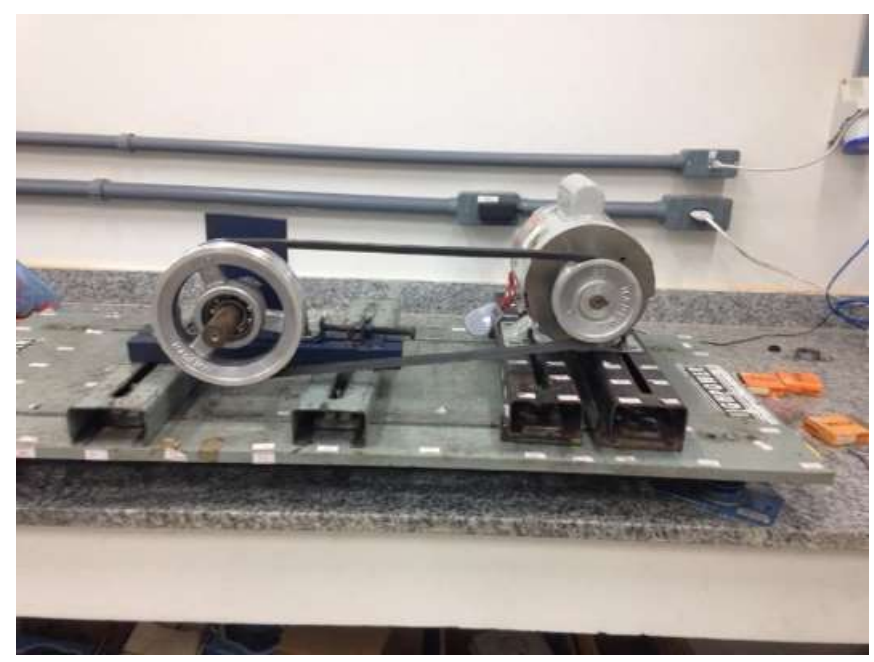

Figura 6. Bancada de Teste. Fonte: Autor (2019). 
A fim de aquecer o rolamento, foram utilizadas lâmpadas incandescente de $500 \mathrm{~W}$, pelo fato de as lâmpadas incandescente terem seu rendimento baixo. Sendo que apenas $5 \%$ da energia elétrica consumida é transformado em luz, os outros 95\% são transformados em calor.

Para conservar o calor construiu-se uma estufa de MDF de $15 \mathrm{~mm}$ de espessura, por deter um coeficiente baixo de condutividade térmica, logo viabiliza o aumento da temperatura na região próxima aos rolamentos, como ilustrado na Figura 7.

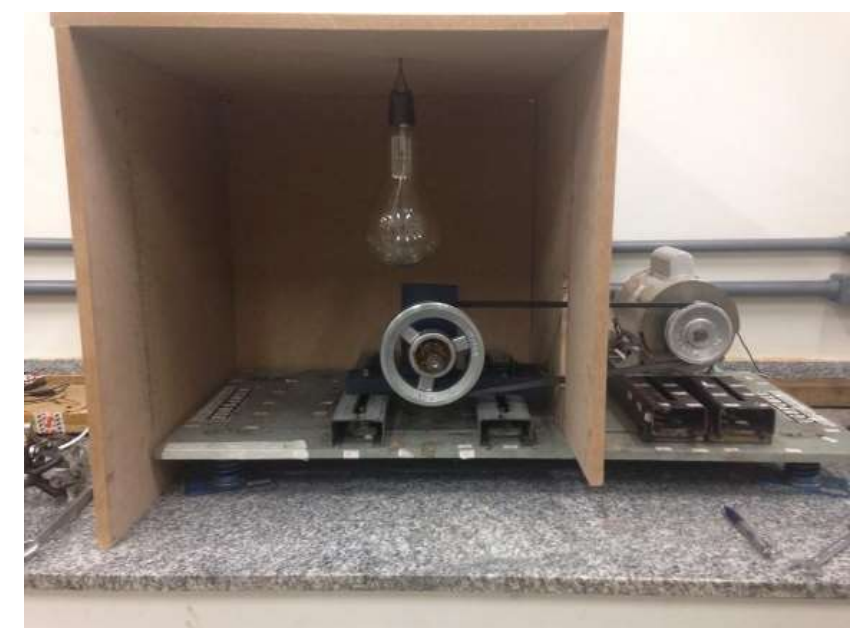

Figura 7. Estufa utilizada para os experimentos. Fonte: Autor (2019).

As polias foram alinhadas utilizado o alinhador de polia SKF TKBA 10 (Figura 8) que permite o alinhamento de polias e rodas dentadas na face lateral. A unidade é anexada magneticamente à face interna ou externa de quase toda polia de correia ou roda.

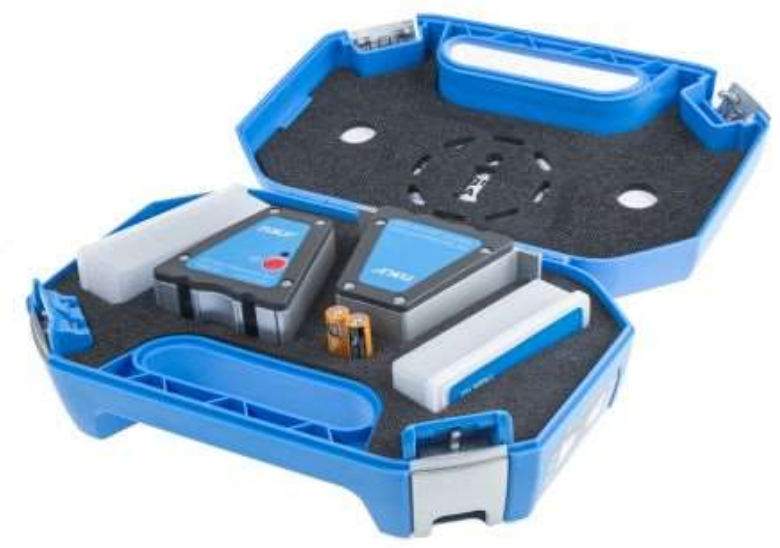

Figura 8. Alinhador de polia SKF TKBA 10. Fonte: Site da SKF. 
A correia utilizada nos testes foi a A-34, este tipo de correia é indicada para transmissão de força/velocidade do motor para o equipamento. Utilizada em máquinas industriais em geral, compressores, serras circulares de bancada, furadeiras de bancada e de coluna, betoneiras, entre outros. Composta à base de borracha natural, que mantém os cordonéis na posição correta e protege a correia contra danos causados pela compressão. Possui tecido de algodão impregnado com borracha natural, que protege os componentes internos da abrasão e do óleo. Conta ainda com fios de fibra sintética que têm como função a transmissão de força.

Os termogramas foram gerados com a Câmera Termográfica SKF TKTI 10. A imagem térmica, apresentada em uma tela de LCD, mostra onde a temperatura está muito quente ou muito fria, permitindo a identificação de problemas potenciais rapidamente

Tal equipamento foi configurado a temperatura ambiente de $25^{\circ}$ Graus Celsius, com interpolação de temperatura, e com o alto número de integração. Com esses parâmetros, conferem temperatura próximas os reais. Apresentada na Figura 9.

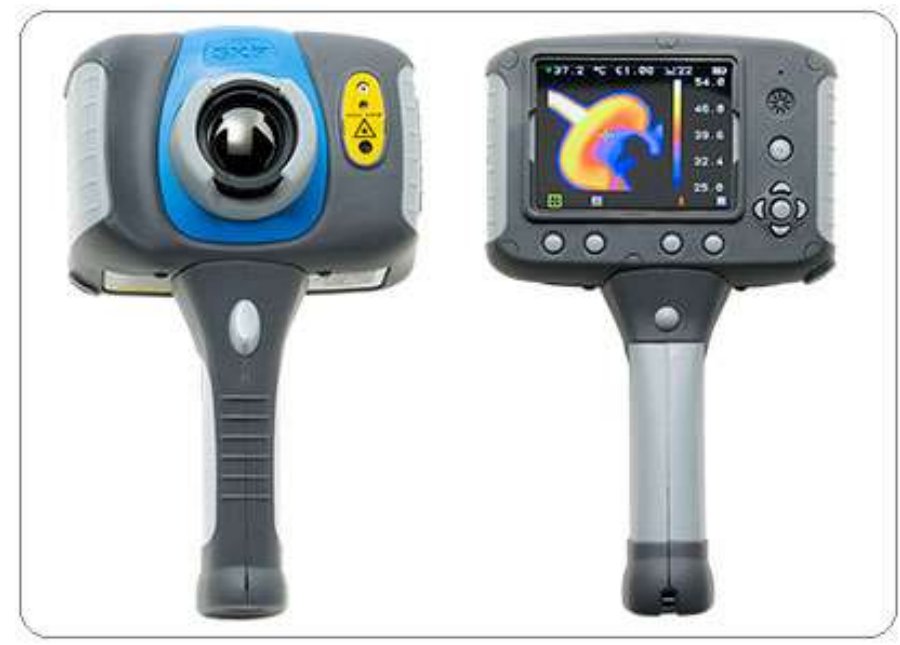

Figura 9. Câmera Termográfica. Fonte: Site da SKF.

\subsection{PRocedimentos}

O experimento teve início com a montagem da bancada, primeiramente foi averiguado se o motor monofásico detinha as condições adequadas para os experimentos. A partir disso, fixou-se o motor 
através de parafusos sextavados, porcas e arruelas na bancada. Em seguida foi acoplado a polia de $90 \mathrm{~mm}$ de diâmetro, no eixo do motor.

Posteriormente, vinculou-se o Rolamento GBR Bearing na polia de $150 \mathrm{~mm}$ de diâmetro, com o uso do Aquecedor Indutivo foi aquecido a temperatura de $100^{\circ} \mathrm{C}$ o conjunto polia-rolamento, para enfim, o conjunto ser acoplado ao outro eixo. Tal eixo também foi fixado na bancada através de parafusos sextavados, porcas e arruelas.

Com isso, submeteu-se a estufa sobre a bancada, e empregou-se da Correia A-34 para interligar ambas as polias.

Após esses procedimentos, utilizou o alinhador de polia SKF TKBA 10, para alinhar o sistema do experimento, pois o desalinhamento de polias aumenta o desgaste em polias e correias, além de aumentar os níveis de vibração e ruído, o que pode resultar em um tempo de parada não programada do equipamento, entre outros benefícios do alinhamento adequado.

Após o alinhamento, mediu-se o volume fixo da graxa a ser estudada, assim submeteu-se a graxa através da aplicação manual direta por espátula no rolamento.

Por fim, ligou-se o motor monofásico e a lâmpada de alta potência, e aguardou-se para o rolamento adquirir a temperatura desejada monitorando através da câmera termográfica SKF, assim retirou-se a amostra de graxa armazenada em potes específicos.

Tal amostra foi contemplada ao Teste de Consistência e ao Teste de Sangria, retirando os dados para analise posteriormente.

Com o fim do experimento, manuseou o Saca Polia de Três Garras Regulável para a retirar a polia de $150 \mathrm{~mm}$ de diâmetro, que, por conseguinte, recolheu-se o rolamento para sua limpeza. Tal rolamento foi submerso a uma solução de querosene para a retirada da graxa, evitando assim contaminações no próximo experimento.

\section{RESULTADOS E DISCUSSÕES}

Foram realizados testes nas três graxas lubrificantes, sendo que a temperatura verificada foi a ambiente, a $50^{\circ} \mathrm{C}$ e $75^{\circ} \mathrm{C}$ no interior dos rolamentos. A partir disso foi possível conceber os seguintes resultados. 
Para a Graxa Azul (Sabão de Lítio), percebe-se que com a análise no Teste de Sangria, a área molhada a $50^{\circ} \mathrm{C}$ não houve alteração em relação a área molhada da graxa a temperatura ambiente $\mathrm{o}$, sendo assim não ocorreu o despreendimento do óleo da graxa. Por outro lado para o Teste de Sangria a $75^{\circ} \mathrm{C}$ transcorreu uma variação negativa de 3,9\%. Tal porcentagem, é considerada normal pois com o tempo de uso o óleo é expulso da graxa, deixando somente o sabão.

Para esse mesmo lubrificante notou-se que a variação de temperatura ascendeu o Grau NLGI das amostras, pois a energia absorvida pelas moléculas foi capaz de romper as ligações intermoleculares e estabelecer novas interações, como também, diminui a resistência ao movimento (fluxo) de forma irreversível do lubrificante. Tais resultados é exemplificado na Tabela 1.

Tabela 1. Resultados Graxa Azul.

\begin{tabular}{cccc}
\hline \multicolumn{5}{c}{ Graxa azul (Sabão de Lítio) } \\
\hline Teste & Amostra Fresca & $\mathbf{5 0}^{\mathbf{0}}$ Graus & $\mathbf{7 5}^{\mathbf{0}}$ Graus \\
\hline Classe (Grau NLGI) & 2 & 3 & 3 \\
\hline Variação (\%) & - & $33 \%$ & $33 \%$ \\
\hline Diâmetro médio (mm) & 33,50 & 33,50 & 32,90 \\
\hline Área Molhada (mm $\mathbf{m m}^{\mathbf{2}}$ & 802,47 & 802,47 & 771,19 \\
\hline Variação $(\mathbf{\%})$ & - & 0,00 & $-3,90$ \\
\hline
\end{tabular}

Para as amostras realizadas com Unigrax CA (Base de Cálcio), evidenciou-se que consistência das amostras usadas a $50^{\circ} \mathrm{C}$ não obteve variações no seu Grau de NLGI em relação à fresca. No entanto a amostra a $50^{\circ} \mathrm{C}$ teve divergência negativa de $10,58 \%$ no Teste de Sangria. Neste caso, a expulsão do óleo sobre graxa foi notória, sendo necessário a re-lubrificação do equipamento .

Bem como, essa graxa foi submetida a uma temperatura superior a máxima que o mesmo suporta, tornando-o o lubrificante volátil e líquido, perdendo suas propriedades de adesividades nas áreas lubrificadas, contribuindo para o gotejamento do mesmo. Com essas transformações, não foi possível adquirir amostras para a realização do Teste de Sangria e Teste de Consistência. Tal observação é mostrada na Tabela 2 seguir. 
Tabela 2. Resultados Graxa Unigrax CA.

Graxa marrom (Base de Calcio)

\begin{tabular}{cccc}
\hline Teste & Amostra Fresca & $\mathbf{5 0}^{\mathbf{0}}$ Graus & $\mathbf{7 5}^{\mathbf{0}}$ Graus \\
\hline Classe (Grau NLGI) & 2 & 2 & - \\
\hline Variação (\%) & - & - & - \\
\hline Diametro médio (mm) & 33 & 31,38 & - \\
\hline Área Molhada $\left(\mathbf{m m}^{2}\right)$ & 776,365 & 694,25 & - \\
\hline Variação $(\%)$ & - & $-10,58$ & - \\
\hline
\end{tabular}

Por fim, para averiguar as análises da Graxa Preta (Hidróxido de Cálcio), conferiu se que para esse lubrificante a consistência das amostras usadas a $50^{\circ} \mathrm{C}$ e $75^{\circ} \mathrm{C}$ não modificaram em relação à fresca.

Além disso, notou-se que uma parcela do volume emergido no rolamento do lubrificante perdeu as propriedades dos agentes de adesividade, com o aumento de temperatura, auxiliando para uma redução da película protetora e consequentemente aumentar o atrito na área lubrificada.

Para a amostra a $50^{\circ} \mathrm{C}$, houve uma pequena redução de $4,04 \%$ na área molhada mostrada no Teste de Sangria em comparativo com a amostra fresca, assim ainda não há a necessidade de tomar medidas corretivas para essa temperatura. Em contrapartida para o diagnóstico a $75^{\circ} \mathrm{C}$ sucedeu um acréscimo de 5,31\% da área molhada resultando no decréscimo da viscosidade do óleo base dessa amostra. Tal prognostico está descrito na Tabela 3.

Tabela 3. Resultados da Graxinha

\begin{tabular}{cccc}
\hline \multicolumn{4}{c}{ Graxa Preta (Hidróxido de Cálcio) } \\
\hline Teste & Amostra Fresca & $\mathbf{5 0}^{\mathbf{0}}$ Graus & $\mathbf{7 5}^{\circ}$ Graus \\
\hline Classe (Grau NLGI) & 2 & 2 & 2 \\
\hline Variação (\%) & - & - & - \\
\hline Diâmetro médio (mm) & 31,75 & 31,167 & 32,5 \\
\hline Área Molhada (mm $\mathbf{m}^{\mathbf{2}}$ & 712,83 & 684,03 & 750,66 \\
\hline Variação (\%) & - & $-4,04$ & 5,31 \\
\hline
\end{tabular}




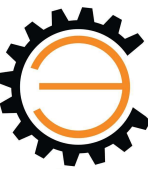

C $\mathrm{EN}$

Universidade Federa de São João del-Rei

\section{CONCLUSÕES}

Com base no sistema montado para este trabalho e as várias análises sobre o Teste de Sangria e o Tense de Consistência é possível avaliar o comportamento de lubrificantes as condições críticas. A tendência desse comportamento foi apresentada nesta pesquisa, evidenciando a influência da temperatura sobre as propriedades das graxas lubrificantes.

Assim conclui-se que é aconselhável o uso da Graxa Azul (Sabão de Lítio), pois essa graxa é altamente aderente aos componentes em elevadas temperaturas garantindo assim estabilidade mecânica no sistema, vedação dos componentes, protegendo contra a corrosão decorrente dos processos de oxidação, e evitando a entrada de impurezas.

Em seguida, é recomendada a Graxa Preta (Hidróxido de Cálcio) para temperaturas próximas a $50^{\circ} \mathrm{C}$, pois sua área molhada teve menor variação se comparada a Unigrax CA (Base de Cálcio), como também, não houve variação no Grau NLGI para ambos lubrificantes.

Logo, analisando a composição de cada lubrificante, observamos que, graxas a base de Lítio compartilham de um alto ponto de gota capazes de trabalhar a altas velocidades e elevadas temperaturas, conferindo a homogeneização de suas propriedades se comparado com a Graxas à base de Cálcio.

Os resultados comprovam que este tipo de análise se adequa à finalidade a que se propôs nesse trabalho e que seu estudo é amplamente utilizado no meio industrial, sendo aplicada em situações reais.

O objetivo do trabalho foi concluído com êxito, visto que se desenvolveu o estudo teórico, testes e análises com base nos conhecimentos adquiridos ao longo da Iniciação Científica. E por fim, para um trabalho futuro pretende-se de modular outros tipos de lubrificantes e observar seu comportamento em condições críticas, a fim de identificar falhas, e assim poder prevê-las antecipadamente garantindo a durabilidade do sistema.

\section{AGRADECIMENTOS}

O discente agradece ao membro do Gep_LASID, Leonardo Vasconcelos Bessa por auxiliar na montagem da bancada, nos testes realizados e em todos os processos deste trabalho, aos membros do Gep_LASID, Elen Kassia e Rafael Rosa, por contribuírem nas duvidas imergidas no decorrer desta 
pesquisa juntamente com os ensinamentos sobre os equipamentos utilizados, ao Ex-membro do Gep_LASID o Daniel Junio a todo auxilio em dificuldades encontradas, ao Prof. Dr. Vinicius e ao Prof. Dr. Jorge Nei Brito por todo suporte nos desafios ocorrentes ao longo desse trabalho possibilitando a viabilidade desta pesquisa, por último, aos colegas da Republica Engenho que colaboraram diretamente ou indiretamente para a pesquisa

O discente é grato também à FAPEMIG e à UFSJ que possibilitaram a realização deste estudo.

\section{DIREITOS AUTORAIS}

Os autores são os únicos responsáveis pelo conteúdo das informações contidas neste artigo.

\section{REFERENCIAS}

ASTM, Standard D217-10, 2010, "Standard Test Methods for Cone Penetration of Lubricating Grease", ASTM International, West Conshohocken, PA, DOI: 10.1520/D0217-10, <www.astm.org>.

BRITO, L.C., PEREIRA J. G., BRITO, J. N. Associação das Técnicas Preditivas: Análise de Vibração e Análise de Graxa, Para Detecção de Falhas em Rolamentos. 2011

CAMPOS, Diogo Carlos Melo de Pinho. Implementação de técnicas e ferramentas para manutenção preditiva na Colep. Dissertação de Mestrado, Faculdade de Engenharia da Universidade do Porto, 2011.

CAVAlCANTI, E. J. C., MORA, N. D., SERRA, T. Z., Estudo do desempenho do óleo lubrificante em pontos diferentes da turbina. 2007.

J. N. Brito, 2002. Desenvolvimento de um Sistema Inteligente Híbrido para Diagnóstico de Falhas em Motores de Indução Trifásicos. Campinas, Faculdade de Engenharia Mecânica, Universidade Estadual de Campinas. 214 p. Tese (Doutorado).

J. R. Stack, T. G. Habetler, and R. G. Harley, 2003. Effects of Machine Speed on the Development and Detection of Rolling Element Bearing Faults. IEEE Power Electron Lett. Vol. 1, No. 1, pp. 19-21.

Noções báscias sobre rolamentos. Disponível em:<www.skf.com/br/products/bearings-unitshousings/principles/general-bearing-knowledge/bearing-basics/index.html >. Acesso em: 15 março. 2019. 

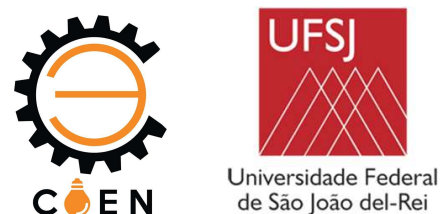

OLIVEIRA, Davi Borges de. Manutenção preditiva; Termografia; Indústria sucroalcooleira; Manutenção preditiva; Termografia; Indústria sucroalcooleira. Trabalho de Conclusão de Curso apresentado ao Centro Universitário de Formiga - UNIFOR-MG, 2012

O que é um rolamento?. Disponível em:< http://www.nsk.com.br/o-que-e-um-rolamento152.htm>. Acesso em: 15 março. 2019.

SKF, M. P., 2011, “Instructions for Use - Test Kit Analysis Grease TKGT 1”. Proc. In CD-ROM by Kit

SOUZA, Valdir Cardoso de. Organização e gerenciamento da manutenção: programação e controle de manutenção / Valdir Cardoso de Souza. - 4a. Ed. - São Paulo: All Printe Editora. 2011.

V. A. D. Silva, J. N. Brito e L. M. R. Baccarini, 2009. Detection of Stator Winding Inter-Turn Short Circuit Using Thermographic Analysis. Proceedings of the 20th International Congress of Mechanical Engineering - COBEM 2009. Gramado - RS, Brazil.

\title{
LUBRICATING GREASE MONITORING UNDER CRITICAL TEMPERATURE CONDITIONS
}

\author{
Gustavo Rodrigues Lacerda (gu-lacerda@hotmail.com) ${ }^{(1)}$, \\ Vinicius Augusto Diniz Silva (viniciusadsilva@ufsj.edu.br) ${ }^{(1)}$ \\ ${ }^{(1)}$ Universidade Federal de São João Del Rei (UFSJ) - Engenharia Mecânica - Praça Frei Orlando, 170
}

ABSTRACT: Lubricants are substances that emerge between two surfaces, form a protective film that has the function of reducing friction, wear, as well as assisting in the control of the temperature and the sealing of the components of machinery and motors, providing the cleaning of the parts. Among these lubricants stands out the grease, a high viscosity pasty lubricant, compounds of mixtures of mineral lubricating oils, salts of fatty acids such as calcium, sodium, lithium, aluminum, barium and magnesium.From this, three types of lubricating greases were determined: lithium soap the grease, based on calcium grease, and put an end to the calcium hydroxide grease. Thus, we analyzed the greases in use on a rigid ball bearing.To analyze the bearing under critical temperature conditions, the SKF grease test kit was used to verify the consistency and properties of the bearings, in addition to verifying the SKF thermographic camera to monitor the temperature inside the bearing. The purpose of the research is to defer which lubricating grease is advisable for this system, allowing longer life and yield for the bearing and analyze the properties and consistencies relating the manufacturing materials of lubricating grease to the increase in temperature.

KEYWORDS: Oil bleeding test. Lubricants. Test of Consistency, Viscosity 